\title{
Produção de mudas de maracujazeiro amarelo sob salinidade da água de irrigação
}

\author{
Production of yellow passion fruit seedlings under irrigation water salinity \\ Producción de plantallas amarillas de pasión bajo salinidad del agua de riego
}

Idelvan José da Silva

ORCID: https://orcid.org/0000-0001-9559-8663

Universidade Federal de Campina Grande, Brasil

E-mail: idelvan3@hotmail.com

Francisco de Assis da Silva

ORCID: https://orcid.org/0000-0003-4558-1147

Universidade Federal de Campina Grande, Brasil

E-mail: agrofdsilva@gmail.com

Pedro Dantas Fernandes

ORCID: https://orcid.org/0000-0001-5070-1030

Universidade Federal de Campina Grande, Brasil

E-mail: pedrodantasfernandes@gmail.com

Mirandy dos Santos Dias

ORCID: https://orcid.org/0000-0002-0160-6069

Universidade Federal de Campina Grande, Brasil

E-mail: mirandydias@gmail.com

Cassiano Nogueira de Lacerda

ORCID: https://orcid.org/0000-0002-4132-1287

Universidade Federal de Campina Grande, Brasil

E-mail: cassianonogueiraagro@gmail.com

André Alisson Rodrigues da Silva

ORCID: https://orcid.org/0000-0001-9453-1192

Universidade Federal de Campina Grande, Brasil

E-mail: andrealisson_cgpb@hotmail.com

Aline Dayanna Alves de Lima Marcelino

ORCID: https://orcid.org/0000-0002-7823-0784 Universidade Federal da Paraíba, Brasil

E-mail: alinedayanna@gmail.com

Armando Rodrigues de Melo

ORCID: https://orcid.org/0000-0002-7952-7264

Universidade Federal de Campina Grande, Brasil

E-mail: armando.melo.7@gmail.com

Lígia Sampaio Reis

ORCID: https://orcid.org/0000-0001-8101-396X Universidade Federal de Alagoas, Brasil E-mail: lavenere_reis@hotmail.com

Robson Felipe de Lima

ORCID: https://orcid.org/0000-0003-4975-6610 Universidade Federal de Campina Grande, Brasil E-mail: robson_felipe88@ hotmail.com

\begin{abstract}
Resumo
O uso de águas com alto teor de sais constitui sério problema na formação de mudas e estabelecimento do maracujazeiro em diferentes áreas da região nordeste, a qual é considerada bastante expressiva na produção do maracujazeiro amarelo. Diante disso, objetivou-se com o presente estudo, avaliar a produção de mudas de maracujazeiro amarelo em resposta a salinidade da água de irrigação. O experimento foi desenvolvido em casa de vegetação. Foram estudados 5 tratamentos, constituídos de cinco níveis de condutividade elétrica da água de irrigação $\left(0,8 ; 1,6 ; 2,4 ; 3,2\right.$ e 4,0 dS m$\left.~^{-1}\right)$, distribuídos em delineamento de blocos casualizados, com 12 repetições, e uma planta por parcela, totalizando 60 unidades experimentais. O efeito dos tratamentos foram avaliados mediante análise de crescimento, das trocas gasosas e da fluorescência da clorofila $a$. A irrigação com água de condutividade elétrica acima de $0,8 \mathrm{dS} \mathrm{m}^{-1}$ afetou negativamente o crescimento do maracujazeiro cv. Redondo Amarelo aos 40 dias após a semeadura. A irrigação com água de $4,0 \mathrm{dS} \mathrm{m}{ }^{-1}$ comprometeu as trocas gasosas e a fluorescência da clorofila a, além de reduzir a taxa de transporte de elétrons da mudas de maracujazeiro.
\end{abstract}

Palavras-chave: Passiflora edulis; Água salina; Fisiologia. 


\begin{abstract}
The use of water with a high salt content is a serious problem in the formation of seedlings and establishment of passion fruit in different areas of the northeast region, which is considered quite expressive in the production of yellow passion fruit. Therefore, the aim of this study was to evaluate the production of yellow passion fruit seedlings in response to the salinity of irrigation water. The experiment was carried out in a greenhouse. Five treatments were studied, consisting of five levels of electrical conductivity of the irrigation water $\left(0.8 ; 1.6 ; 2.4 ; 3.2\right.$ and $\left.4.0 \mathrm{dS} \mathrm{m}^{-1}\right)$, distributed in a randomized block design, with 12 replications, and one plant per plot, totaling 60 experimental units. The effects of the treatments were obtained by analyzing the growth, gas exchange and fluorescence of chlorophyll a. Irrigation with water with electrical conductivity above $0.8 \mathrm{dS} \mathrm{m}^{-1}$ negatively affected the growth of passion fruit cv. Round Yellow at 40 days after sowing. Irrigation with $4.0 \mathrm{dS} \mathrm{m} \mathrm{m}^{-1}$ water compromised gas exchange and chlorophyll a fluorescence, in addition to reducing the electron transport rate of passion fruit seedlings.
\end{abstract}

Keywords: Passiflora edulis; Saline water; Physiology.

\title{
Resumen
}

El uso de agua con alto contenido en sal constituye un grave problema en la formación de plántulas y el establecimiento de maracuyá en diferentes zonas de la región noreste, lo que se considera bastante expresivo en la producción de maracuyá amarilla. Por lo tanto, el objetivo de este estudio fue evaluar la producción de plántulas de maracuyá amarilla en respuesta a la salinidad del agua de riego. El experimento se llevó a cabo en un invernadero. Se estudiaron cinco tratamientos, consistentes en cinco niveles de conductividad eléctrica del agua de riego $(0.8 ; 1.6 ; 2.4$; 3.2 y $4.0 \mathrm{dS} \mathrm{m}^{-1}$ ), distribuidos en un diseño de bloques al azar, con 12 repeticiones, y una planta por parcela, totalizando 60 unidades experimentales. Los efectos de los tratamientos se evaluaron analizando el crecimiento, el intercambio de gases y la fluorescencia de la clorofila $a$. El riego con agua con conductividad eléctrica superior a 0,8 $\mathrm{dS} \mathrm{m}{ }^{-1}$ afectó negativamente el crecimiento de maracuyá cv. Amarillo redondo a los 40 días después de la siembra. El riego con $4.0 \mathrm{dS} \mathrm{m}^{-1}$ de agua comprometió el intercambio de gases y la fluorescencia de la clorofila a, además de reducir la tasa de transporte de electrones de las plántulas de maracuyá.

Palabras clave: Passiflora edulis; Agua salina; Fisiologia.

\section{Introdução}

O maracujá (Passiflora edulis Sims) é uma das culturas de maior relevância comercial, constituindo 95\% dos pomares no país, gerando emprego e renda em diversos municípios (IBGE, 2019; Cavalcante et al., 2019). Nesse contexto, o Brasil se destaca como o maior produtor e consumidor mundial de maracujá, produzindo 593.429 toneladas, em 41.584 ha, dos quais 64,5\% da produção corresponde a região Nordeste (IBGE, 2019).

Mesmo sendo considerada a principal produtora do maracujazeiro, a irregularidade na distribuição de chuvas, altas temperaturas e elevadas taxas de evapotranspiração tem limitado a disponibilidade de água de boa qualidade no semiárido brasileiro, tornando-se necessário a utilização de águas com teores de sais elevados como uma alternativa para suprir a demanda hídrica, principalmente no período de estiagem, quando os poços e açudes da região tem níveis de sais elevados na água, comprometendo a formação de mudas e o estabelecimento da cultura (Bezerra et al., 2016; Nascimento et al., 2017).

Por ser considerada uma planta de ciclo curto (semi-perene) (Faleiro e Junqueiro, 2016), esta cultura exige do produtor a renovação das áreas plantadas, obrigando-o à produção ou aquisição de mudas de alta qualidade. Visto que, no semiárido brasileiro, a escassez de água em quantidade e boa qualidade vem forçando o uso de águas com excesso de sais.

O uso de águas com alto teor de sais constitui um sério problema, pois o excesso de sais na solução do solo, causa alterações na fisiologia, crescimento e desenvolvimento das plantas devido ao efeito osmótico, toxicidade de íons e desequilíbrio nutricional (Dias et al., 2016; Taiz et al., 2017; Costa et al., 2019).

$\mathrm{Na}$ fisiologia, por exemplo, o estresse salino induz o fechamento estomático e, consequentemente, reduz a condutância estomática, com alterações na concentração intercelular de $\mathrm{CO}_{2}$ na câmara subestomática $(C i)$ e causa redução da transpiração, o que resulta em diminuição da taxa fotossintética (Arif et al., 2020). Além disso, a limitação das trocas gasosas, pelo fechamento estomático, resulta em desequilíbrio entre a fase fotoquímica e o metabolismo do carbono, devido à diminuição da difusão do $\mathrm{CO}_{2}$ (Taiz et al., 2017). 
O crescimento inicial das plantas em geral, inclusive do maracujazeiro amarelo, é bastante sensível ao excesso de sais durante a formação das mudas (Nascimento et al., 2017) De acordo com Ayers e Westcot (1999), o maracujazeiro amarelo é considerado sensível aos sais, com declínio do crescimento quando a salinidade do extrato de saturação do solo é superior a 1,3 $\mathrm{dS} \mathrm{m}^{-1}$.

Diante disso, objetivou-se avaliar a produção de mudas de maracujazeiro amarelo em resposta a salinidade da água de irrigação.

\section{Metodologia}

O experimento foi desenvolvido entre os meses de abril e maio de 2021 em ambiente protegido (casa de vegetação) da Universidade Federal de Campina Grande (UFCG), na Unidade de Engenharia Agrícola, localizado na cidade de Campina Grande, Paraíba, nas coordenadas geográficas $07^{\circ} 15^{\prime} 18^{\prime \prime} \mathrm{S}, 35^{\circ} 52^{\prime} 28^{\prime \prime} \mathrm{W}$, a uma altitude de $550 \mathrm{~m}$.

Os dados de temperatura e umidade relativa do ar no período da pesquisa estão na Figura 1.

Figura 1. Temperatura máxima (T máx.) e mínima (T min.) $\left({ }^{\circ} \mathrm{C}\right)$ e umidade relativa média (UR $(\%)$, observadas durante o período de condução do experimento. Campina Grande, PB. 2021.

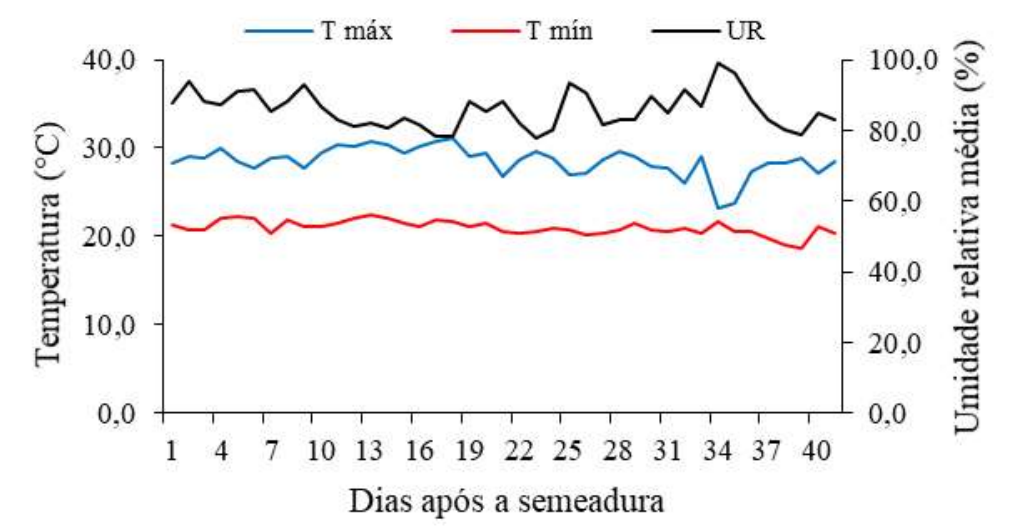

Fonte: Autores.

Foram estudados 5 tratamentos, constituídos de cinco níveis de condutividade elétrica da água de irrigação $(0,8 ; 1,6$; 2,4; 3,2 e 4,0 dS m $\mathrm{m}^{-1}$ ), distribuídos em delineamento de blocos casualizados, com 12 repetições, e uma planta por parcela, totalizando 60 unidades experimentais.

As mudas foram produzidas em sacos de polietileno com capacidade para $0,5 \mathrm{dm} 3$, no qual foram preenchidos com solo, cujas características químicas (Tabela 1) foram realizada conforme metodologia descrita por Teixeira et al. (2017).

Tabela1. Atributos químicos do solo. Campina Grande, PB.

\begin{tabular}{|c|c|c|c|c|c|c|c|c|c|c|c|c|}
\hline $\mathrm{pH}$ & $\mathrm{P}$ & K & $\mathrm{Ca}$ & $\mathrm{Na}$ & $\mathrm{Mg}$ & $\mathrm{Al}$ & $\mathrm{H}$ & SB & CTC & V & $\mathrm{m}$ & MO \\
\hline \multirow{2}{*}{6,5} & $\mathrm{mg} \mathrm{dm}^{-3}$ & \multirow[b]{2}{*}{0,24} & \multicolumn{6}{|c|}{..cmolc dm ${ }^{-3}$. } & & \multicolumn{2}{|c|}{........\% \% ........... } & $\mathrm{mg} \mathrm{dm}^{-3}$ \\
\hline & 79 & & 14,9 & 0,51 & 5,4 & 0,0 & 0,9 & 7,74 & 16,54 & 94,9 & 0,0 & 8,1 \\
\hline
\end{tabular}

CTC a pH 7,0; Método EMBRAPA; Extração: Água (pH); Mehlich (P, K, Na); KCl 1N (Ca, Mg e Al); Acetato de Cálcio pH 7,0 (H + Al). Fonte: Autores.

A semeadura foi realizada de modo a distribuir duas sementes por sacos de forma equidistante na profundidade de 1 cm. As sementes de maracujazeiro cv. Redondo Amarelo, com poder germinativo de 87\%. Após a estabilização da emergência, aos 20 dias após a semeadura (DAS) foi realizado o desbaste, deixando apenas uma planta por recipiente. 
As águas salinas foram preparadas dissolvendo-se os sais $\mathrm{NaCl}, \mathrm{CaCl}_{2} .2 \mathrm{H}_{2} \mathrm{O}$ e $\mathrm{MgCl}_{2} \cdot 6 \mathrm{H}_{2} \mathrm{O}$, na proporção equivalente de 7:2:1, entre $\mathrm{Na}^{+}, \mathrm{Ca}^{2+}$ e $\mathrm{Mg}^{2+}$, respectivamente, em água de abastecimento local $\left(\mathrm{CEa}=0,4 \mathrm{dS} \mathrm{m}^{-1}\right)$. Essa proporção de sais é comumente encontrada em fontes de água utilizadas para irrigação, em pequenas propriedades do Nordeste brasileiro (Medeiros et al., 2003), com base na relação entre CEa e a concentração de sais $\left(10^{*} \mathrm{mmolc} \mathrm{L}^{-1}=\mathrm{CEa} \mathrm{dS} \mathrm{m}^{-1}\right)$, extraída de Richards (1954).

As irrigações foram realizadas com água de abastecimento local $\left(0,4 \mathrm{dS} \mathrm{m}^{-1}\right)$ uma vez ao dia a partir da semeadura, no início da manhã, de modo a deixar a umidade do solo próximo a capacidade de campo. A partir dos 30 DAS, iniciou-se as aplicações com água salinas.

A adubação foi realizada conforme recomendação de Novais (1991), sendo aplicado em cada unidade experimental, 0,555 gramas de ureia como fonte de $\mathrm{N}, 1,25 \mathrm{~g}$ de fosfato monoamônio (MAP) como fonte de fósforo e 0,625 $\mathrm{g}$ de cloreto de potássio como fonte $\mathrm{K}_{2} \mathrm{O}$, parceladas aos 15 e 30 DAS.

Foi aplicado a cada dez dias uma solução de micronutrientes na concentração de $1,0 \mathrm{~g} \mathrm{~L}^{-1}$ do produto comercial Dripsol® micro contendo: $\mathrm{Mg}$ (1,1\%); Zn (4,2\%); B (0,85\%); Fe (3,4\%); Mn (3,2\%); Cu (0,5\%); Mo (0,05\%), via foliar, nas faces adaxial e abaxial, com o uso de um borrifador.

O controle de pragas e doenças foram feitas de forma preventiva e controle quando houve o aparecimento do causador para isso foi utilizado produtos químicos seletivos a base de Imidacloprido e Abamectina utilizando-se no preparo da calda $1 \mathrm{~g}$ para $10 \mathrm{~L}$ e $2,5 \mathrm{~mL}$ para $10 \mathrm{~L}$ respectivamente.

Aos 40 DAS foram determinados os efeitos dos tratamentos sobre as variáveis de crescimento: altura de planta (AP) e diâmetro de caule (DC); sobre as variáveis de trocas gasosas: condutância estomática $(g s)$, transpiração $(E)$, concentração interna de $\mathrm{CO}_{2}(\mathrm{Ci})$ e taxa de assimilação de $\mathrm{CO}_{2}(A)$; fluorescência da clorofila $a$ mediante a determinação da fluorescência inicial $(F o)$, fluorescência máxima $(F m)$, Fluorescência variável $(F v)$, eficiência quântica do PSII $(F v / F m)$, eficiência fotoquímica do PSII $(F v / F o)$ e rendimento quântico basal dos processos fotoquímicos no PSII $(F o / F m)$; também foram avaliados a radiação fotossinteticamente ativa (PAR - Clip), a fluorescência inicial antes do pulso de saturação $(F s)$ e taxa de transporte de elétrons $(E T R)$.

A altura de planta foi medida tomando-se como referência a distância do colo da planta à inserção do meristema apical e o diâmetro de caule $(\mathrm{mm})$ foi medido a $1 \mathrm{~cm}$ do colo da planta, com auxílio de um paquímetro digital. A determinação das trocas gasosas foi realizada na terceira folha, contada a partir do ápice do ramo principal da planta, sendo utilizada irradiação de $1200 \mu \mathrm{mol}$ fótons $\mathrm{m}^{-2} \mathrm{~s}^{-1}$ e fluxo de ar de $200 \mathrm{~mL} \mathrm{~min}^{-1}$, usando-se o equipamento portátil de medição de trocas gasosas (Infra Red Gas Analyser - IRGA, marca ADC BioScientific Ltd, modelo LC-Pro), em condições naturais de temperatura do ar, concentração de $\mathrm{CO}_{2}$.

As mesmas folhas foram utilizadas para as medições da fluorescência da clorofila $a$ (protocolo $F v / F m$ ), usando-se o fluorômetro de pulso modulado, modelo OS5p da Opti Science. As leituras foram realizadas em folhas adaptadas ao escuro e, para simular a adaptação das folhas ao escuro, foi utilizado pinças que acompanham o fluorômetro. Após 30 minutos de adaptação da folha ao escuro, foram realizadas as leituras.

Ainda com o uso do fluorômetro de pulso modulado, foram avaliados, em condições de claro, usando-se o protocolo Yield e aplicando-se uma fonte de iluminação actínica, com pulso multiflash saturante, acoplado a um clipe de determinação da radiação fotossinteticamente ativa (PAR - Clip) a fluorescência inicial antes do pulso de saturação $(F s)$ e taxa de transporte de elétrons (ETR).

Os dados foram submetidos ao teste de normalidade da distribuição (teste de Shapiro-Wilk) ao nível de 0,05 de probabilidade, e subsequente à análise de variância pelo teste $\mathrm{F}$, quando significativos foi realizado à análise regressão polinomial linear e quadrático, utilizando-se o software Sisvar (Ferreira, 2019). 


\section{Resultados e Discussão}

$\mathrm{O}$ aumento da condutividade elétrica da água de irrigação afetou negativamente a altura de planta (AP) e o diâmetro da de haste (DH) do maracujazeiro cv. Redondo Amarelo, de acordo com as equações de regressão (Figura 1 A e B), constatase efeito linear, com decréscimo de 31,0 e 46,0\% para AP e DH, respectivamente, ao comparar em termos relativos os resultados obtidos nas plantas irrigadas com água de alta salinidade $\left(4,0 \mathrm{dS} \mathrm{m}^{-1}\right)$ em relação a baixa salinidade $\left(0,8 \mathrm{dS} \mathrm{m}^{-1}\right)$.

Figura 1. Altura de planta (A) e diâmetro da haste (B) de mudas de maracujazeiro amarelo em função da salinidade da água de irrigação aos 40 dias após a semeadura.
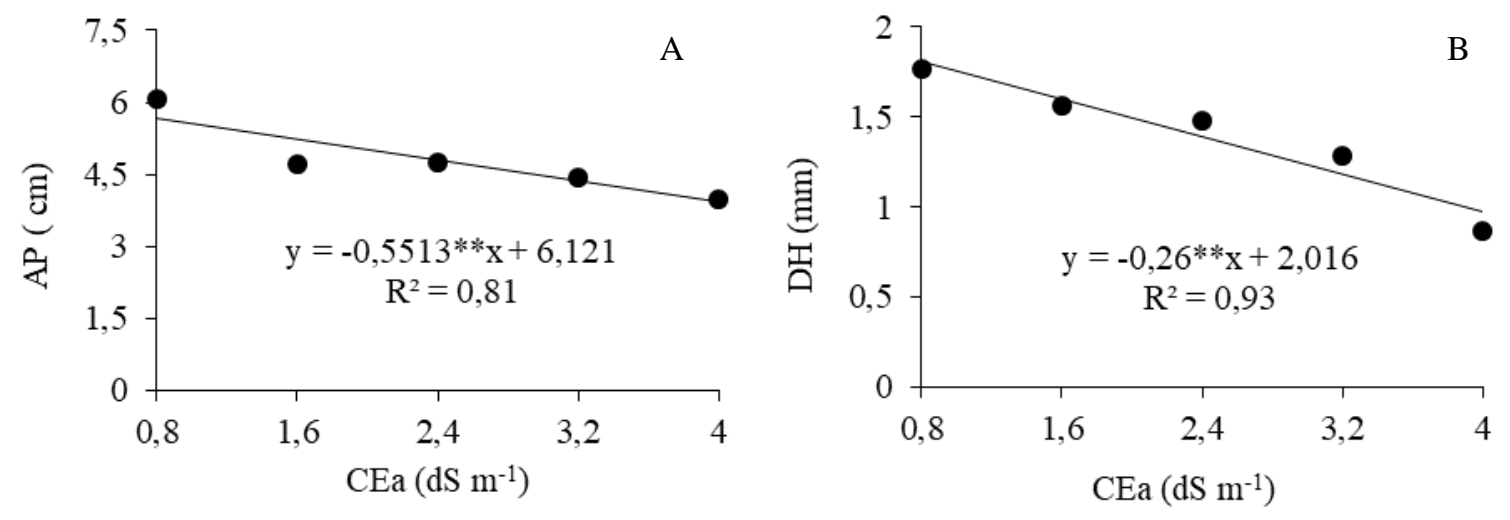

Fonte: Autores.

A redução observada para a AP e DH ocorre em virtude da restrição na absorção de água pela planta causada pelo efeito osmótico oriundo do acúmulo de sais no sistema radicular, provocando alterações hormonais, nutricionais e modificando as atividades metabólicas das células no processo de alongamento celular (Taiz et al., 2017; Tanaka et al., 2018). De acordo com Kummar, sob estresse salino as plantas adotam vários mecanismos para sobreviver em tais condições, dentre eles, modificações nos níveis morfológico, fisiológico e bioquímico. Diminuindo o gasto de energia, como consequência, o crescimento é influenciado negativamente (Liu e Jiang, 2015).

Resultados semelhantes foram obtidos por Silva et al. (2019) avaliando o efeito do estresse salino (0,7 a 2,8 $\left.\mathrm{dS} \mathrm{m}^{-1}\right)$ sob mudas de maracujazeiro amarelo, foi constatado reduções de 19,3\% na AP e 18,5\% no DC, ao comparar as plantas irrigadas com água de maior salinidade em relação as irrigadas com o menor nível salino.

A condutância estomática $(g s)$, transpiração $(E)$ e taxa de assimilação de $\mathrm{CO}_{2}(A)$ foram reduzidas com incremento da condutividade elétrica da água de irrigação. A $g s$ foi de 0,15 para $0,08 \mathrm{~mol} \mathrm{~m}^{-2} \mathrm{~s}^{-1}$ quando se utilizou na irrigação água de condutividade elétrica de 0,8 e 4,0 dS m$~ m^{-1}$, respectivamente, com redução de 45,5\% na abertura estomática ao se aumentar a salinidade da água (Figura 2A).

A transpiração foi reduzida ao se elevar a salinidade da água de irrigação, decrescendo de 1,94 para 1,23 mmol de $\mathrm{H}_{2} \mathrm{O} \mathrm{m}^{-2} \mathrm{~s}^{-1}$ entre as plantas irrigadas com água de menor e de maior salinidade, inibindo 36,3\% (Figura 1B). A magnitude dos danos causados pela utilização de águas de alta salinidade, variam de acordo com tempo de aplicação, concentração, tolerância da cultura, bem como do volume de água transpirado pela planta (Schossler et al., 2012). 
Figura 2. Condutância estomática (A), transpiração (B), concentração interna de $\mathrm{CO}_{2}(\mathrm{C})$ e taxa de assimilação de $\mathrm{CO} 2$ (D) de mudas de maracujazeiro amarelo em função da salinidade da água de irrigação aos 40 dias após a semeadura.
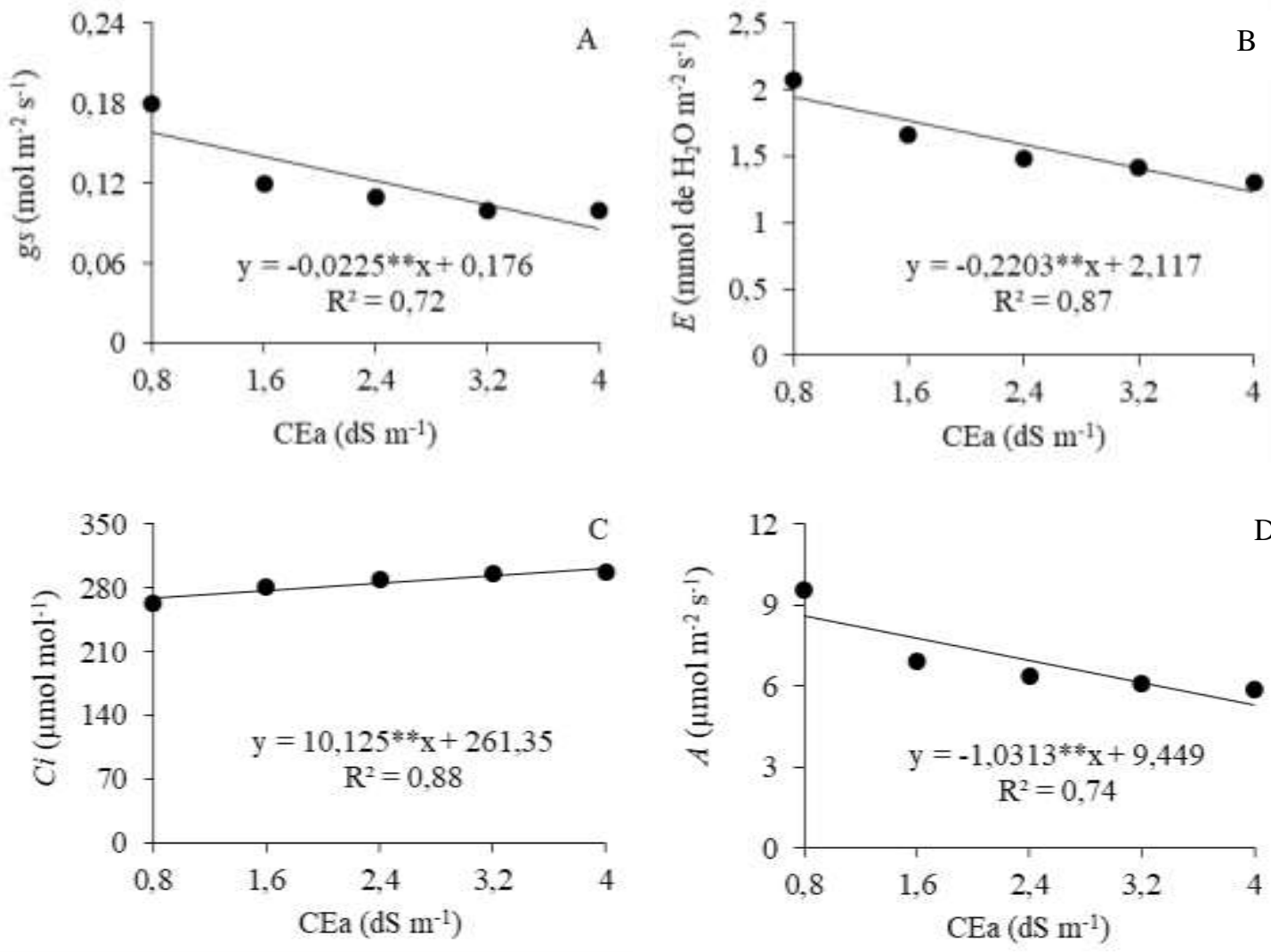

Fonte: Autores.

A concentração interna de carbono teve tendência contraria a gs e $E$, com média de 2679,4 e $301,8 \mu \mathrm{mol} \mathrm{mol}^{-1}$ quando se utilizou na irrigação água de condutividade elétrica de 0,8 e 4,0 dS m$~ m^{-1}$, respectivamente, aumentando $12,0 \%$ nesse parâmetro, ao se elevar a salinidade da água (Figura 2C).

O fechamento estomático reduziu a condutância estomática, a transpiração e aumentou a concentração de carbono no interior da célula, influenciando na redução da taxa de assimilação de $\mathrm{CO}_{2}$, ao se elevar a salinidade da água de irrigação, decrescendo de 8,62 e 5,32 $\mu \mathrm{mol} \mathrm{m} \mathrm{m}^{-2} \mathrm{~s}^{-1}$ entre as plantas irrigadas com água de menor e de maior salinidade, provocando redução de $38,2 \%$ (Figura $2 \mathrm{D}$ ).

O aumento da condutividade elétrica da água de irrigação de 0,8 para $4,0 \mathrm{dS} \mathrm{m}^{-1}$ aumentou a fluorescência inicial das mudas de maracujazeiro, partindo de 526,8 para 576,5 elétrons quantum ${ }^{-1}$, correspondendo a um aumento de 9,4\% (Figura 3A). Em contrapartida, a fluorescência máxima e a fluorescência variável foram reduzidas ao se elevar a salinidade da água de irrigação, decrescendo de 2047,2 para 1612,4 e de 1520,3 para 1035,9 entre as plantas irrigadas com água de menor e de maior salinidade, com inibição de 21,2 e 31,8\%, respectivamente (Figura 3B e C). 
Figura 3. Fluorescência inicial (A), Fluorescência máxima (B), fluorescência variável (C), eficiência quântica do PSII (D), eficiência fotoquímica do PSII (E) e rendimento quântico basal dos processos fotoquímicos no PSII (F) de mudas de maracujazeiro amarelo em função da salinidade da água de irrigação aos 40 dias após a semeadura.
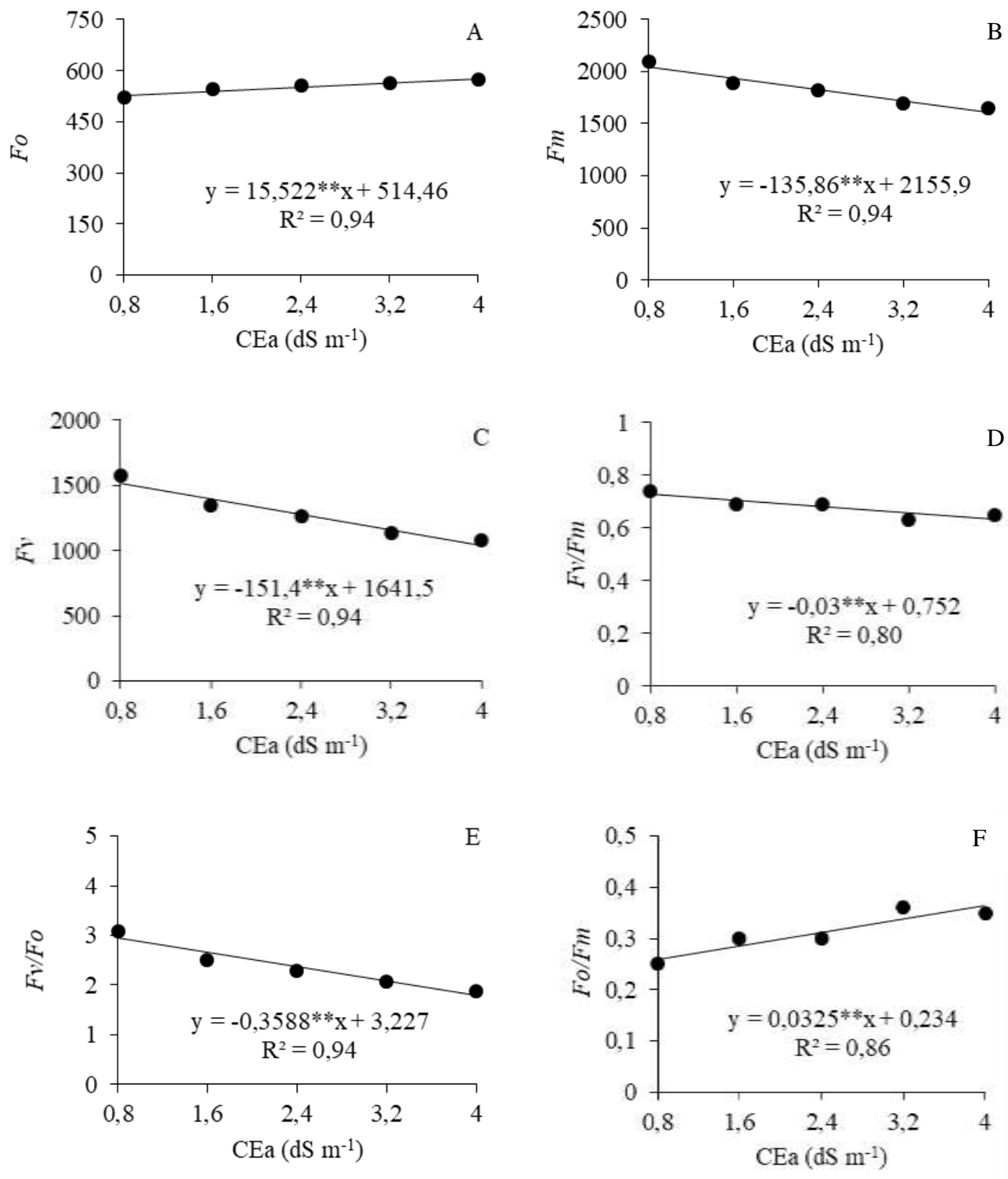

Fonte: Autores.

A eficiência quântica máxima do fotossistema II, foi inibida de 0,72 para 0,63 elétrons quantum ${ }^{-1}$, indicando redução de $13,1 \%$ ao se aumentar a condutividade elétrica da água de irrigação de 0,8 para $4,0 \mathrm{dS} \mathrm{m}^{-1}$ (Figura 3D). Esse aumento na concentração salina da água de irrigação também comprometeu 39,0\% (2,93 para 1,79 elétrons quantum $\left.{ }^{-1}\right)$ a eficiência fotoquímica do fotossistema II $(F v / F o)$ das mudas de maracujazeiro Redondo Amarelo (Figura 3E).

O rendimento quântico basal dos processos fotoquímicos no PSII $(F o / F m)$, também foi comprometido pela salinidade, sendo constatado aumento nos índices da relação $F o / F m$ partindo de 0,26 para 0,36 ao aumentar a condutividade da água de irrigação de 0,8 para 4,0 dS m$~^{-1}$. O incremento corrido observado nesse estudo, é indicativo de que as plantas estavam sofrendo 
estresse, uma vez que, plantas não estressadas os valores normais na relação Fo/Fm variam entre 0,14 e 0,20 (Rohácek, 2002; Zanandrea et al., 2006).

Os baixos índices de $F v, F v / F m$ e $F v / F o$ foram induzidos pelas alterações na $F o$ e na relação $F o / F m$, proporcionando baixa eficiência quântica do PSII, uma vez que, todos os valores de $F v / F m$ foram abaixo de 0,75 , indicando ocorrência de degradação no aparato fotossintético das plantas submetidas a níveis crescente da salinidade via água de irrigação, pois de acordo com Silva et al. (2014) e Soares et al. (2018), valores normais que não causam danos ao aparato fotossintético das plantas variam entre 0,75 e 0,85 .

Neste estudo, a baixa eficiência fotoquímica das mudas de maracujazeiro redondo amarelo, irrigadas com água salinas, corroboram com a redução ocorrida na taxa de assimilação de $\mathrm{CO}_{2}$ (Figura 2D), confirmando que os fatores de ordem estomática atuaram no processo fotossintético, limitando a disponibilidade de ATP e NADPH eficazes na regeneração da RuBisCO.

Para parâmetros não fotoquímicas houve efeito significativo apenas para a fluorescência inicial antes do pulso de saturação (F') e a taxa de transporte de elétrons (ETR). A fluorescência inicial antes do pulso de saturação e à taxa de transporte de elétrons foram reduzidas de 177,8 para 154,7 e de 28,9 para 17,5, respectivamente, com aumento da salinidade da água de irrigação de 0,8 para 4,0 dS m ${ }^{-1}$ (Figura 4A e B).

A redução da taxa de transporte de elétrons, pode ter ocorrido em virtude do aumento do potencial osmótico em decorrência da aplicação de sal, reduzindo a disponibilidade de água para as plantas. Os transportadores de elétrons fotossintéticos são inativados com o aumento do potencial osmótico, podendo atingir nível irreversível (Tatagiba et., 2014). Com base nessa informação, os valores de ETR obtidos nesse estudo com mudas de maracujazeiro sob salinidade da água de irrigação, estão coerentes com a os obtidos na taxa de assimilação de $\mathrm{CO}_{2}$, no qual foi constatada redução com o aumento da salinidade (Figura 2D).

Figura 4. Fluorescência inicial antes do pulso de saturação (A), taxa de transporte de elétrons (B) de mudas de maracujazeiro amarelo em função da salinidade da água de irrigação aos 40 dias após a emergência.
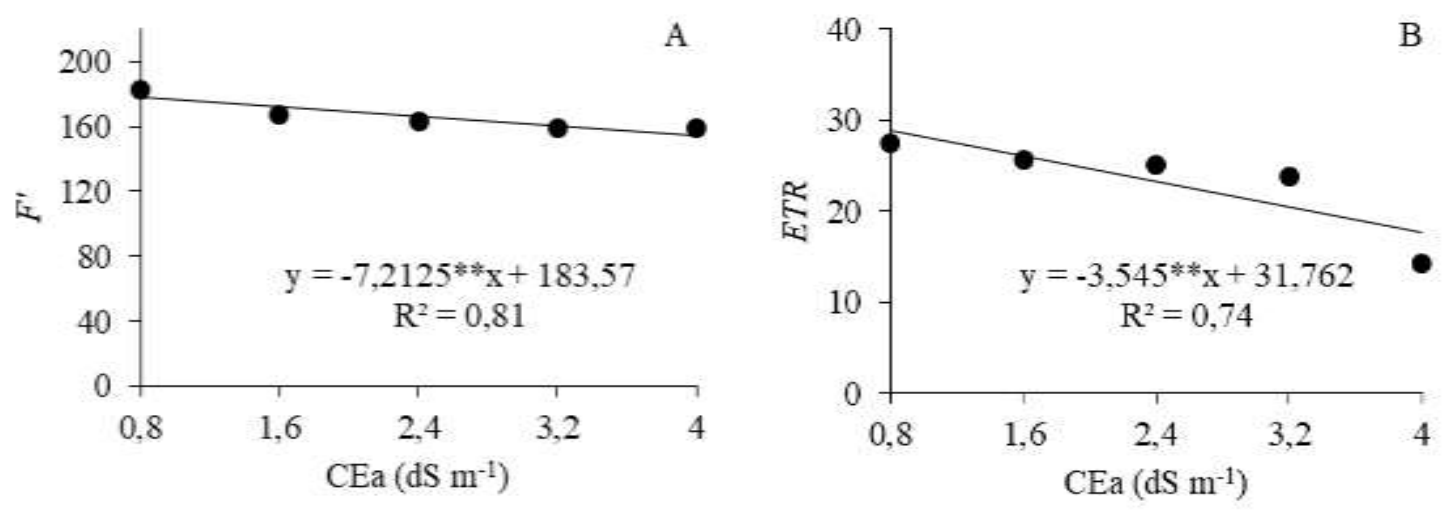

Fonte: Autores.

\section{Conclusão}

A irrigação com água de condutividade elétrica acima de $0,8 \mathrm{dS} \mathrm{m}^{-1}$ afeta negativamente o crescimento do maracujazeiro cv. Redondo Amarelo aos 40 dias após a semeadura.

A irrigação com água de $4,0 \mathrm{dS} \mathrm{m}{ }^{-1}$ compromete as trocas gasosas e a fluorescência da clorofila $a$, além de reduzir a taxa de transporte de elétrons das mudas de maracujazeiro.

Em pesquisas futuras, recomenda-se estudar a aplicação de atenuantes no cultivo do maracujazeiro amarelo como 
estratégias de mitigação dos efeitos da salinidade, especialmente, para o semiárido brasileiro, visto que nessa região, a salinidade é um dos principais fatores ambientais que mais limita o crescimento e desenvolvimento das plantas.

\section{Agradecimentos}

A coordenação de Aperfeiçoamento de Pessoal de Nível Superior (CAPES) e ao Programa de Pós-graduação em Engenharia Agrícola da Universidade Federal de Campina Grande.

\section{Referências}

Arif, Y., Singh, P., Siddiqui, H., Bajguz, A., \& Hayat, S. (2020). Salinity induced physiological and biochemical changes in plants: An omic approach towards salt stress tolerance. Plant Physiology and Biochemistry, 156, 64-77.

Ayers, R.S. \& Westcot, D.W. (1999). A qualidade de água na agricultura. (2a ed.), UFPB, FAO, 153p.

Bezerra, J. D., Pereira, W. E., Silva, J. M. D., \& Raposo, R. W. C. (2016). Crescimento de dois genótipos de maracujazeiro-amarelo sob condições de salinidade1. Revista Ceres, 63, 502-508.

Cavalcante, N. R., Viana, A. P., Almeida Filho, J. E., Pereira, M. G., Ambrósio, M., Santos, E. A., Sousa, C. M. B (2019). Novel selection strategy for half-sib families of sour passion fruit Passiflora edulis (Passifloraceae) under recurrent selection. Genetics and Molecular Research, 18(2), 2-12.

Costa, M. E., Nascimento, E. K. Á., Oliveira Miranda, N., Pimenta, A. S., Santos Rodrigues, A. P. M., \& Mendonça Júnior, A. F. (2019). Efeito do biochar sobre condutividade elétrica e ph de solos irrigados com água salina. Educamazônia-Educação, Sociedade e Meio Ambiente, 23(2), $189-204$.

Dias, N. S., Blanco, F. F., Souza, E. R., Ferreira, J. F. S., Souza Neto, O. N., Queiroz, I. S. R. (2016). Efeitos dos sais na planta e tolerância das culturas à salinidade. In: Gheyi, H. R., Dias, N. S., Lacerda, C. F., Gomes, E. N. Manejo da salinidade na agricultura: Estudos básicos e aplicados. INCTSal, 151-162.

Moraes Echer, M., Guimarães, V. F., Krieser, C. R., Abucarma, V. M., Klein, J., Santos, L., \& Dallabrida, W. R. (2006). Uso de bioestimulante na formação de mudas de maracujazeiro amarelo. Semina: Ciências Agrárias, 27(3), 351-359. Faleiro, F. G.,

Junqueira, N. T. V. Maracujá: o produtor pergunta, a Embrapa responde. Embrapa Cerrados-Livro técnico, 2016.341 p.

Ferreira, D. F. (2019). SISVAR: A computer analysis system to fixed effects split plot type designs. Revista brasileira de biometria, 37(4), 529-535.

Instituto Brasileiro de Geografia e Estatística (IBGE). Produção agrícola municipal. (2019). https://sidra.ibge.gov.br/tabela/5457\#resultado

Kumar, A., Singh, S., Gaurav, A. K., Srivastava, S., \& Verma, J. P. (2020). Plant growth-promoting bacteria: biological tools for the mitigation of salinity stress in plants. Frontiers in Microbiology, 11, 1216.

Liu, M., \& Jiang, Y. (2015). Genotypic variation in growth and metabolic responses of perennial ryegrass exposed to short-term waterlogging and submergence stress. Plant Physiology and Biochemistry, 95, 57-64.

Medeiros, J. F. de. Qualidade de água de irrigação e evolução da salinidade nas propriedades assistidas pelo GAT nos Estados de RN, PB e CE (2003). (Dissertação Mestrado). Universidade Federal da Paraíba, Campina Grande.

Nascimento, E. S., Cavalcante, L. F., Gondim, S. C., Souza, J. T. A., Bezerra, F. T. C., \& Bezerra, M. A. F. (2017). Formação de mudas de maracujazeiro amarelo irrigadas com águas salinas e biofertilizantes de esterco bovino. Revista Agropecuária Técnica, 38(1), 1-8.

Novais, R. D., Neves, J. C. L., \& Barros, N. D. (1991). Ensaio em ambiente controlado. Métodos de pesquisa em fertilidade do solo, 1, 89-253.

Richards, L. A. Diagnosis and improvement of saline and alkali soils. (1954) Washington: U.S, Department of Agriculture.

Roháček, K. (2002). Chlorophyll fluorescence parameters: the definitions, photosynthetic meaning, and mutual relationships. Photosynthetica, 40(1), 13-29.

Schossler, T. R., Machado, D., Zuffo, A. M., Andrade, F., \& Piauilino, A. (2012). Salinidade: efeitos na fisiologia e na nutrição mineral de plantas. Enciclopédia Biosfera, 8(15).

Shrivastava, P., \& Kumar, R. (2015). Soil salinity: A serious environmental issue and plant growth promoting bacteria as one of the tools for its alleviation. Saudi journal of biological sciences, 22(2), 123-131.

Silva, L. D. A., Brito, M. E., Sá, F. V. D. S., Moreira, R. C., Soares Filho, W. D. S., \& Fernandes, P. D. (2014). Mecanismos fisiológicos em híbridos de citros sob estresse salino em cultivo hidropônico. Revista Brasileira de Engenharia Agrícola e Ambiental, 18,1 -7.

Silva, A. A., Veloso, L. L., Lima, G. S. D., Azevedo, C. A., Gheyi, H. R., \& Fernandes, P. D. (2021). Hydrogen peroxide in the acclimation of yellow passion fruit seedlings to salt stress1. Revista Brasileira de Engenharia Agrícola e Ambiental, 25, 116-123.

Soares, L. A. D. A., Fernandes, P. D., Lima, G. S. D., Brito, M. E. B., Nascimento, R. D., \& Arriel, N. H. C. (2018). Physiology and production of naturallycolored cotton under irrigation strategies using salinized water. Pesquisa Agropecuária Brasileira, 53, 746-755.

Taiz, L., Zeiger, E., Moller, I. M., Murph, A. Fisiologia e desenvolvimento vegetal. (2017). (6a ed.), Artmed. 
Research, Society and Development, v. 10, n. 9, e29810918178, 2021

(CC BY 4.0) | ISSN 2525-3409 | DOI: http://dx.doi.org/10.33448/rsd-v10i9.18178

Tanaka, H., Yamada, S., Masunaga, T., Yamamoto, S., Tsuji, W., \& Murillo-Amador, B. (2018). Comparison of nutrient uptake and antioxidative response among four Labiatae herb species under salt stress condition. Soil Science and Plant Nutrition, 64(5), 589-597.

Tatagiba, S. D., Moraes, G. A. B. K., Nascimento, K. J. T., \& Peloso, A. F. (2014). Limitações fotossintéticas em folhas de plantas de tomateiro submetidas a crescentes concentrações salinas, Revista Engenharia Na Agricultura - Reveng, 22(2), 138-149.

Teixeira, P.C., Donagemma, G.K., Fontana, D., Teixeira, W.G. Manual de métodos de análise de solo (2017). (3a ed.), Embrapa Solos, Brasília.

Zanandrea, I., de Lima Nassi, F., Turchetto, A. C., Braga, E. J. B., Peters, J. A., \& Bacarin, M. A. (2006). Efeito da salinidade sob parâmetros de fluorescência em Phaseolus vulgaris. Current Agricultural Science and Technology, 12(2). 